\title{
(2) OPEN ACCESS \\ Characteristics of potential concussive events in three elite football tournaments
}

\author{
Nicholas Armstrong 일 ${ }^{1}$ Mario Rotundo, ${ }^{1}$ Jason Aubrey, ${ }^{1}$ Christopher Tarzi, ${ }^{1}$ \\ Michael D Cusimano ${ }^{1,2,3}$
}

${ }^{1}$ Neurosurgery, St. Michael's Hospital, Toronto, Ontario, Canada

${ }^{2}$ Neurosurgery, University of Toronto, Toronto, Ontario,

Canada

${ }^{3}$ Dalla Lana School of Public Health, University of Toronto, Toronto, Ontario, Canada

Correspondence to Dr Michael D Cusimano, Neurosurgery, St. Michael's Hospital, Toronto, ON M5B 1W8, Canada; cusimanom@smh.ca

NA and MR contributed equally.

Received 20 March 2019 Revised 20 June 2019 Accepted 20 June 2019 Published Online First 22 July 2019
Check for updates

(C) Author(s) (or their employer(s)) 2020. Re-use permitted under CC BY-NC. No commercial re-use. See rights and permissions. Published by BMJ.

To cite: Armstrong $\mathrm{N}$, Rotundo M, Aubrey J, et al. Inj Prev 2020:26:334-338.

\section{ABSTRACT \\ Objective Identify patterns in the nature and} characteristics of potential concussive events (PCEs) in football.

Methods This study analysed the incidence and characteristics of PCEs that occurred during the 2014 and 2018 Fédération Internationale de Football Association World Cups, and the 2016 UEFA Euro Cup. PCEs were defined as direct head collision incidents resulting in the athlete being unable to immediately resume play for at least $5 \mathrm{sec}$ following impact.

Results A total of 218 incidents were identified in 179 matches (1.22 per match, 36.91 per 1000 hours of exposure). The most common mechanism of PCE was elbow-to-head $(28.7 \%, n=68)$. The frontal region was the most frequently affected location of impact with $22.8 \%(n=54)$.

Conclusion Our study defined the identification, prevalence and nature of PCEs in professional international soccer tournaments. Our findings indicate the different contexts and mechanisms of head contact and contact to different regions of the head can be associated with varying signs of concussion. The results highlight targets for future injury prevention strategies.

\section{INTRODUCTION}

In recent years, research into sport-related concussions (SRCs) has identified football, also known as soccer in some countries, as a high-risk sport. ${ }^{1}$ Research has revealed that professional football players sustain head injuries and concussions at marginally lower rates compared to sports such as American football and ice hockey. ${ }^{2}{ }^{3}$ The Center for Disease Control and Prevention reported that sports and recreation-related traumatic brain injury (TBI) was responsible for 3.4 million visits to emergency departments between 2001 and 2012 in the USA alone, and approximately 70\% of reported cases involved persons 19 years or younger. ${ }^{4}$ As the most played sport globally, football produces more head injury events than any other contact sport. ${ }^{56}$ The long-term effects of concussive events on recreational and professional players is not only a burden to the individual player but also to societies and health systems around the world. In 2006, the lifetime cost of TBI in the USA was estimated to be US\$ 60 billion annually, including medical costs and lost productivity. ${ }^{7}$ SRCs in American children aged 5-18 from 2000 to 2004 resulted in approximately US\$ 29 million in total hospital charges. ${ }^{8}$

Research suggests that professional football players who sustained concussive blows during their careers had impaired cognitive functioning including memory, planning and visuo-perceptual processing. ${ }^{9}$ Investigating the characteristics of potential concussive events (PCEs) could elucidate the type of PCE that is more likely to produce acute concussive symptoms, as well as those that may be more likely to cause long-term neurological impairments. The term PCE is not used synonymously with concussion, instead PCEs capture a wide range of in game head collisions which may or may not lead to the clinical diagnosis of concussion. It is more encompassing and relates to all those events that could signify that a concussion has occurred. To this end, it is important to determine the mechanisms of injury and locations of contact to the head that are associated with the greatest number of concussive symptoms. Having this sort of knowledge may help in strategies to reduce the burden of brain injury in sport. For example, it is conceivable that impacts to more sensitive regions of the head could result in a more severe head injury, and should thus be assessed with greater caution. This understanding could also help in the development of protective gear to reduce the effects of impact.

Our study aims to investigate the characteristics of PCEs among three professional tournaments over 4 years. Characteristics of PCEs included time of the event, location of the event, location of the impact on the head, mechanism of injury and concussive symptoms displayed in the players involved. It is imperative to understand the nature of these injuries if regulatory sporting agencies such as the Fédération Internationale de Football Association (FIFA) and other stakeholders are to reduce the number of PCEs that occur in football. This knowledge will also have implications for education and training, as well as for rule development and enforcement to reduce brain injury.

\section{METHODS}

The study analysed the 2014 and 2018 FIFA World Cups (WC), and the 2016 Euro Cup (EC). Between the three tournaments, a total of 179 professional international matches were played. The present study extends our prior research on assessment of PCE in elite soccer with a distinct focus on the characteristics of PCEs. ${ }^{10}$

The 2018 FIFA WC data were collected by a team of four independent reviewers. To ensure inter-observer agreement with the previous 2014 FIFA WC and 2016 EC data ${ }^{10}$ and to confirm understanding of the variables, five non-2018 FIFA WC international games were assessed by all 


\begin{tabular}{ll}
\hline Table 1 & Description of variables used in data collection \\
\hline Category & Variable \\
\hline Prior to PCE & Direction of play before injury \\
\hline & Action of player before injury \\
\hline During PCE & Event in game prior to injury \\
\hline & Whether player had head contact \\
\hline & Area in soccer field that injury occurred \\
\hline Time elapsed in game at time of injury \\
\hline After PCE & Team winning at time of injury \\
\hline & Mechanism of injury \\
\hline Impact location \\
\hline Previous injury in game for player \\
\hline Time of stoppage of play \\
Personnel assessing player \\
Description of assessment \\
Duration of assessment \\
External evidence of injury \\
\hline Treatment received \\
Immediate observable effects of hit \\
\hline Player placed on stretcher \\
Reaction of player to injury \\
\hline Fouls/penalties given \\
\hline Player removed from remainder of game \\
\hline
\end{tabular}

PCE, potential concussive event.

four independent reviewers to record PCE. Once all reviewers achieved a Cohen's kappa coefficient value of greater than 0.90 , the 64 games were divided among the four reviewers ensuring each game was assessed by two independent reviewers. Reviewers noted all PCEs and non-PCE control events (eg, ankle, knee and arm injuries). After all games were reviewed, an interobserver agreement (Cohen's kappa) for identification of PCE's was 0.916 (95\% CI 0.901 to 0.950 ). Basic demographic information pertaining to each player's age, height, weight, position, body mass index and club was collected, along with the variables outlined in table 1. Cohen's kappa coefficient for the observed variables was 0.987 (95\% CI 0.974 to 0.994 ). Information was verified independently by a fifth observer, who also resolved any discrepancies.

As per our prior definition, we classified a PCE as any event in which a player had sustained head contact and was unable to immediately resume play within five seconds after contact. ${ }^{10}$ Events in which a player sustained head contact with a ball or other object that resulted in a stoppage of play were included. In player-to-player contact, we defined 'Player 1 ' as the one that sustained head contact, while 'Player 2' was defined as the player without head contact. If both players sustained head contact during a PCE, then 'Player 1' was defined as the one that
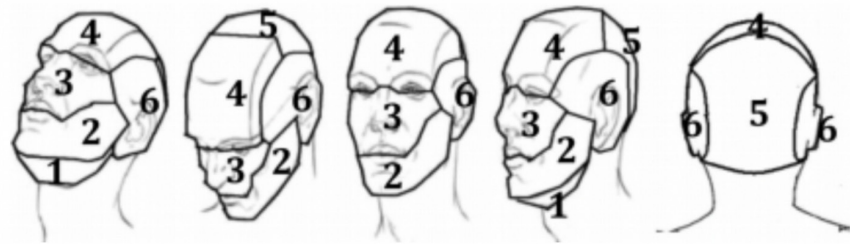

Figure 1 Recorded regions of head impact location involved in PCEs These include 1) interior surface of the mandible, 2) anterior surface of the mandible, 3) nasal area and maxilla, 4) frontal region, 5) parietooccipitalregion, and 6) temporal region.

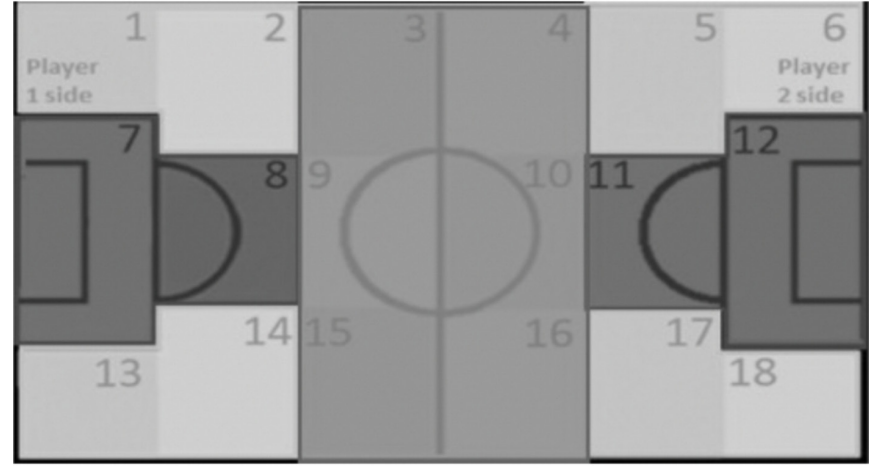

Figure 2 Recorded regions of the field where PCEs occurred, including the Goal Region (dark), Centre Region (medium), and Wing Region (light).

required a longer amount of time to return to play. The impact location on the head and area of the field of the PCE was categorised into the following regions, based on prior work ${ }^{10}$ (figures 1 and 2 , respectively).

In accordance with other video concussion studies, we also recorded the immediate observable effects on the players in the video footage to screen for potential signs of concussion. ${ }^{11-16}$ These signs included: being slow to get up, clutching of the head, dazed/disorientation, loss of consciousness, seizure-like behaviour and signs of obvious disequilibrium.

\section{Data analysis}

Descriptive statistics were reported as means, counts, or frequencies and their associated percentages. All statistical analysis was done in STATA V.13.

\section{RESULTS}

A total of 218 incidents were identified in 179 matches of the 2014 WC, 2016 EC and 2018 WC (1.22 per match, 36.91 per 1000 hours of exposure). Of the 218 incidents, 19 involved a head injury to both 'Player 1' and 'Player 2', resulting in a total of 237 PCEs across all three tournaments (1.32 per match, 40.12 per 1000 hours of exposure).

Over half the incidents leading to PCEs $(54.1 \%)(n=118)$ occurred during the first half of the match, $40.8 \% \quad(n=89)$ occurred in the second half and 5.0\% $(n=11)$ occurred in overtime. Incidents most frequently occurred in the goal region of the field $(39.4 \%, n=86)$, while $30.3 \%(n=66)$ of incidents occurred in the wing region and $30.3 \%(n=66)$ occurred in the centre region. $54.6 \%(n=119)$ of incidents occurred when the game was tied, while 22.9\% $(\mathrm{n}=50)$ occurred when Player 1's team was winning and $22.5 \%(n=49)$ occurred when Player 1 's team was losing.

The most common mechanism of PCE was elbow-to-head $(28.7 \%, n=68)$, of which $91.2 \%(n=62)$ resulted in two or more signs of concussion (table 2, figure 3 ). Other common mechanisms of PCE included head-to-head $(23.2 \%, n=55)$ of which $85.5 \%(n=47)$ resulted in two or more signs of concussion, and hand/fist-to-head $(15.2 \%, n=36)$ where $94.4 \%(n=34)$ resulted in two or more signs of concussion (table 2 ). In the goal region specifically, injuries originated from head to head (33\%), elbow to head $(21 \%)$, or ball to head (14\%) impact. A $\chi^{2}$ test of independence was performed to examine the association between the location on the pitch (goal vs non-goal) and incidence of head-to-head contact. The relationship was significant, $\chi^{2}(1$, $\mathrm{n}=237)=10.3, \mathrm{p}=0.0013$. 
Table 2 Number of concussive signs observed by head impact location

\begin{tabular}{|c|c|c|c|c|}
\hline \multirow[b]{2}{*}{ Impact location } & \multirow[b]{2}{*}{ Total } & \multicolumn{3}{|c|}{ Number of concussive symptoms } \\
\hline & & 0 & 1 & 2 or more \\
\hline Inferior surface of the mandible (1) & $4(1.7 \%)$ & 0 & $1(25 \%)$ & $3(75 \%)$ \\
\hline Anterior surface of the mandible (2) & $43(18.1 \%)$ & 0 & $2(4.7 \%)$ & $41(95.5 \%)$ \\
\hline Nasal area and maxilla (3) & $39(16.5 \%)$ & $1(2.6 \%)$ & $4(10.3 \%)$ & $34(87.2 \%)$ \\
\hline Frontal region (4) & $54(22.8 \%)$ & $2(3.7 \%)$ & $3(5.6 \%)$ & $49(90.7 \%)$ \\
\hline Parietal and occipital region (5) & $47(19.8 \%)$ & $1(2.1 \%)$ & $6(12.8 \%)$ & $40(85.1 \%)$ \\
\hline Temporal regions (6) & $46(19.4 \%)$ & 0 & $5(10.9 \%)$ & $41(89.1 \%)$ \\
\hline Not clear from video & $4(1.7 \%)$ & $1(25 \%)$ & $1(25 \%)$ & $2(50 \%)$ \\
\hline Total & $237(100 \%)$ & $5(2.1 \%)$ & $22(9.3 \%)$ & $210(88.6 \%)$ \\
\hline
\end{tabular}

(1) interior surface of the mandible, (2) anterior surface of the mandible, (3) nasal area and maxilla, (4) frontal region, (5) parieto-occipitalregion, and (6) temporal region.

The frontal region was the most frequently affected location of impact with $22.8 \%(n=54)$, where $90.7 \%(n=49)$ showed two or more signs of concussion. Other frequent impact locations included parietal and occipital region $(19.8 \%, \mathrm{n}=47)$, temporal region $(19.4 \%, \mathrm{n}=46)$, anterior surface of the mandible $(18.1 \%$, $\mathrm{n}=43)$, and nasal/maxilla region $(16.5 \%, \mathrm{n}=39)$ (table 2$)$. However, the variation in incidence was not significant between regions, $\chi^{2}(34, \mathrm{n}=229)=43.2, \mathrm{p}=0.13$. Most players $(88.6 \%$, $\mathrm{n}=210$ ) showed two or more signs of concussion (table 2 ).

\section{DISCUSSION}

The acute and long-term implications of concussions have a significant impact on personal well-being and the healthcare system as a whole. Research continues to identify an elevated concussion risk among athletes at all levels of sport. While concussion awareness has improved and new policies have been introduced regarding concussion protocol, further attention regarding prevention initiatives is warranted. The findings presented here provide important information regarding the characteristics of PCEs in football and in doing so may enhance the development of prevention initiatives.

Based on video observations of the 2014 and 2018 FIFA WC and the 2016 EC, most incidents (40\%) occurred within the goal region of the pitch. 15 of these involved two players, for a total 102 PCEs in the goal region. More than half $(54.6 \%)$ of PCEs occurred while these high stakes games were tied. The most common mechanisms of PCE overall were elbowto-head (28.7\%), head-to-head (23.2\%) and hand/fist-to-head (15.2\%). However, in the goal region specifically, the distribution changed; injuries stemmed predominantly from head to head (33\%), elbow to head (21\%), or ball to head (14\%) impact. There was a significant association between the goal region and

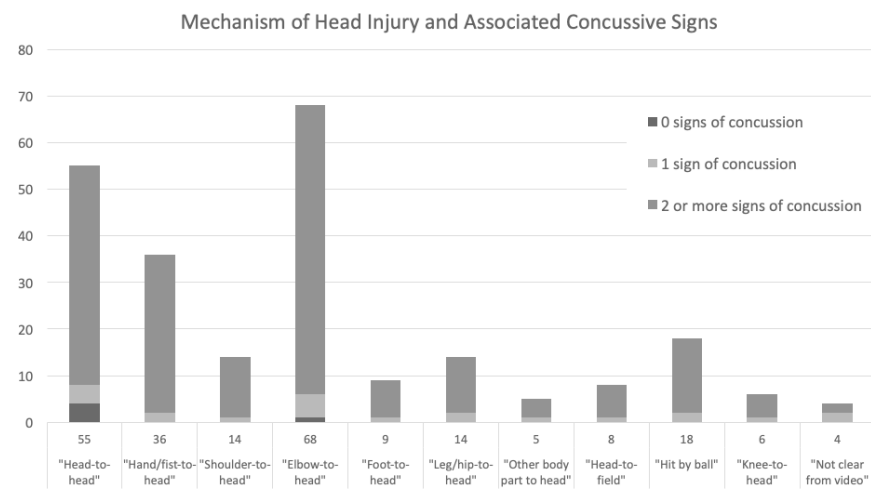

Figure 3 The incidence of each recorded mechanism of PCEand the associated number of subsequently observable signs of concussion. the incidence of head-to-head impacts. This finding speaks to the possibility that players on both teams may be willing to risk more to win and more to defend in this region of the pitch, as actions that transpire here may decide the game. For example, both forwards and defenders, in their respective roles, are more inclined to use a header potentially increasing the likelihood of head to head contact. Moreover, defenders may adopt a more aggressive style of play in this region of the pitch, increasing the likelihood of player to player (eg, head, elbow, hand/fist to head) contact. Finally, players are often crowded together in the goal regions on free-kicks and corner-kicks, which increases the risk of an impact to the head. Future research on how players approach contact with the ball and other players in these highrisk areas of the field may reveal a method of reducing the risk of head contact.

In addition, the findings pertaining to the most common mechanisms of PCE provide additional insight into possible prevention efforts. As mentioned, the most common mechanisms of PCE in all three tournaments were elbow to the head, head to head and hand/fist to head. This is consistent with previous literature. ${ }^{17-19}$ While these actions may be exacerbated at different times during the game and at different locations on the pitch, they are also part of regular play. Our results show that elbow to head injuries occur because players often defend themselves by running and jumping with their elbows flexed for protection leading to dangerous contact with nearby players. While modifying an athlete's style of play is challenging, if consequences for high elbows, such as a yellow card, were implemented and young football players were coached accordingly these types of behaviours may decrease over time in the sport.

While all forms of concussion pose health risks, long-term neurological impairments are of increasing concern among medical professionals. To advance the understanding of the type of PCE that may produce acute concussive symptoms as well as those associated with long-term impairments, the research presented here identified the head regions most frequently struck and those associated with the greatest number of concussive symptoms.

The frontal region (22.8\%), parietal and occipital region (19.8\%), temporal region (19.4\%) and the anterior surface of the mandible $(18.1 \%)$ were struck most frequently. Blows to the anterior surface of the mandible produced two or more concussive symptoms in $95.5 \%$ of cases, followed closely by the frontal region (90.7\%) and temporal regions (89.1\%) (figure 4). Depending on the nature of the strike and region of the head contact, different linear and rotational forces may be generated. Brain injuries due to linear acceleration are often focal, while rotational forces tend to produce more diffuse damage and more 


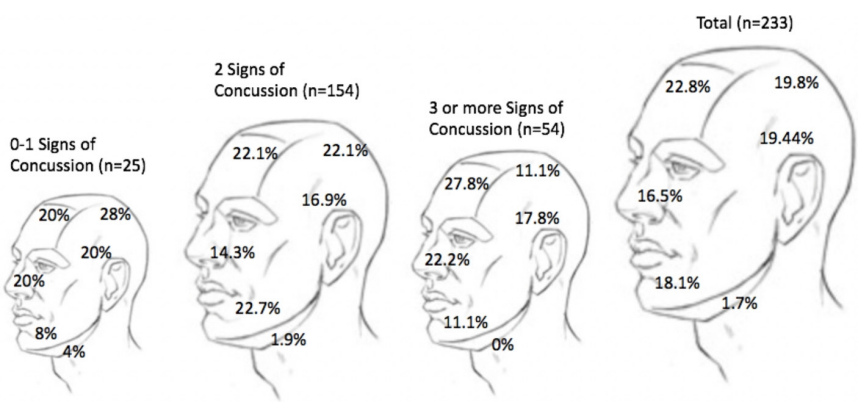

Figure 4 The proportion of PCEs associated with observable signs of concussion, stratified by head region. As outlined in the methods, recorded head regions include the interior surface of the mandible, anteriorsurface of the mandible, nasal and maxilla area, frontal region, parieto-occipital region, and temporal region. The size of the head represents the sample size associated with each group and is smaller for the smallergroups and larger for the larger sized groups.

relative brain motion than any other kinematic parameter. ${ }^{20} 21$ Linear impacts to the superior-inferior axis of the head tend to produce less rotational force due to the impact force being transmitted through the head's centre of gravity and neck. ${ }^{22} 23$ It is likely that these linear superior-inferior forces are comparable to those experienced in purposeful heading of the ball, where the player will contract his/her neck muscles to absorb the impact. ${ }^{23}$ Since research suggests that concussions involve a combination of both linear and rotational forces, ${ }^{20-22}$ it is possible that unexpected blows to the temporal or lateral mandibular region create a more multidirectional force, making them more hazardous to the brain. Further biomechanical research specific to soccer is required to investigate these possibilities. Thorough neurological

\section{What is already known on the subject}

Incidence of potential concussive events (PCEs) in professional football. A total of 218 incidents were identified in 179 matches of the 2014 WC, 2016 EC and 2018 WC (1.22 per match, 36.91 per 1000 hours of exposure).

- Most common mechanism of PCE was elbow-to-head $(28.7 \%, n=68)$.

- Most frequent impact location on the head was the frontal region $22.8 \%(n=54)$.

- Other relevant characteristics of PCEs in football including time of incident, location and whether injured player was on the winning or losing team.

- Number of concussive signs displayed correlated with region of the head that was involved in the impact.

\section{What this study adds}

The findings provide insight into possible PCE prevention efforts in professional football.

- The findings of this study can be applied to develop a better understanding of how to minimise the incidence and severity of PCEs in football and the mitigate burden of brain injury in sport on the healthcare system.

- Ultimately, promoting and enforcing enhanced concussion prevention initiatives in elite football can have an impact at all levels of the game. examination of the injured player immediately following injury and a progressive, stepwise rehabilitation period afterwards is important to protect and promote brain health among professional and recreational soccer players. ${ }^{24}$

Our study intended to investigate the prevalence, identification and nature of PCEs in professional international soccer tournaments. Our findings indicate that different contexts and mechanisms of head contact and contact to different regions of the head can be associated with varying signs of concussion. Further research will continue to provide important information, the findings of this study can be applied to develop a better understanding of how to minimise the incidence and severity of PCEs in football and the mitigate burden of brain injury in sport on the healthcare system. What changes and how these changes must be formulated so as not to greatly attenuate the benefit of sport participation or disturb the flow of the game remains a future goal. ${ }^{25}$ While secondary prevention involving proper assessment of players and avoidance of premature return to play is widely accepted, ${ }^{24}$ we believe that increased efforts at promoting and enforcing enhanced primary prevention initiatives in elite football can have an important and long-term impact at all levels of the game.

\section{LIMITATIONS}

The reviewers in this study were unable to control the movement of the camera, image quality, resolution of the athlete of interest and angles available. These variables have the potential to influence the quality of the data collected. However, digital video recordings have been shown to be a valid method of analysing situational factors, injury mechanisms and signs of injury related to concussion. ${ }^{12141526-30}$ Additionally, the identification of the signs of concussion relies on the interpretation of players' reactions to the injurious events. Given the possibility that soccer players sometimes exaggerate or feign injuries to draw fouls, it is possible that observable signs of concussion like clutching of the head were feigned to gain possession of the ball. No patient data were utilised for this study and all data are in the public domain. As such, future work could refine our results by access to medical and biomarker assessments of players.

\section{CONCLUSION}

Our study intended to investigate the prevalence, identification and nature of PCEs in professional international soccer tournaments. Our findings indicate that different contexts and mechanisms of head contact and contact to different regions of the head can be associated with varying signs of concussion. The findings presented here provide important information regarding the characteristics of PCEs in football and in doing so may enhance the development of prevention initiatives. Ultimately, promoting and enforcing enhanced concussion prevention initiatives in elite football can have an impact at all levels of the game.

Funding This work is supported by the Canadian Institutes of Health Research Strategic Team Grant in Applied Injury Research \#TIR-103946 and the Ontario Neurotrauma Foundation.

Competing interests None declared.

Patient consent for publication Not required.

Ethics approval St. Michael's research ethics board waived the need for approval. Provenance and peer review Not commissioned; externally peer reviewed. Data availability statement Data are available upon reasonable request.

Open access This is an open access article distributed in accordance with the Creative Commons Attribution Non Commercial (CC BY-NC 4.0) license, which permits others to distribute, remix, adapt, build upon this work non-commercially, 
and license their derivative works on different terms, provided the original work is properly cited, appropriate credit is given, any changes made indicated, and the use is non-commercial. See: http://creativecommons.org/licenses/by-nc/4.0/.

ORCID iD

Nicholas Armstrong http://orcid.org/0000-0002-9470-9437

\section{REFERENCES}

1 Conder RL, Conder AA. Sports-related concussions. N C Med J 2015;76:89-95.

2 Delaney JS, Al-Kashmiri A, Correa JA. Mechanisms of injury for concussions in university football, ice hockey, and soccer. Clin I Sport Med 2014:24:233-7.

3 Zuckerman SL, Kerr ZY, Yengo-Kahn A, et al. Epidemiology of sports-related concussion in NCAA athletes from 2009-2010 to 2013-2014: incidence, recurrence, and mechanisms. Am J Sports Med 2015;43:2654-62.

4 Coronado VG, Haileyesus T, Cheng TA, et al. Trends in sports- and recreation-related traumatic brain injuries treated in US emergency departments: the National Electronic Injury Surveillance System-All Injury Program (NEISS-AIP) 2001-2012. J Head Trauma Rehabil 2015:30:185-97.

5 Cantu RC, Mueller FO. Catastrophic football injuries: 1977-1998. Neurosurgery 2000:47:673-5.

6 Broglio SP, Vagnozzi R, Sabin M, et al. Concussion occurrence and knowledge in italian football (soccer). J Sport Sci Med 2010;9:418-30.

7 Langlois JA, Rutland-Brown W, Wald MM. The epidemiology and impact of traumatic brain injury: a brief overview. J Head Trauma Rehabil 2006;21:375-8.

8 Yang J, Phillips G, Xiang H, et al. Hospitalisations for sport-related concussions in US children aged 5 to 18 years during 2000-2004. Br I Sports Med 2008;42:664-9.

9 Matser JT, Kessels AG, Jordan BD, et al. Chronic traumatic brain injury in professional soccer players. Neurology 1998;51:791-6.

10 Cusimano MD, Casey J, Jing R, et al. Assessment of head collision events during the 2014 FIFA World Cup tournament. JAMA 2017;317:2548-9.

11 Makdissi M, Davis G. The reliability and validity of video analysis for the assessment of the clinical signs of concussion in Australian football. J Sci Med Sport 2016:19:859-63.

12 Hutchison MG, Comper P, Meeuwisse WH, et al. A systematic video analysis of National Hockey League (NHL) concussions, part I: who, when, where and what? $\mathrm{Br}$ J Sports Med 2015;49:547-51.

13 Andersen TE, Tenga A, Engebretsen $L$, et al. Video analysis of injuries and incidents in Norwegian professional football. Br J Sports Med 2004;38:626-31.

14 Gardner AJ, Howell DR, Levi CR, et al. Evidence of Concussion Signs in National Rugby League Match Play: a Video Review and Validation Study. Sports Med Open 2017;3.
15 Lincoln AE, Caswell SV, Almquist JL, et al. Video incident analysis of concussions in boys' high school lacrosse. Am J Sports Med 2013;41:756-61.

16 Comper $\mathrm{P}$, Hutchison M. Acute clinical signs and outcome of concussions in national hockey League (NHL) players. Br J Sport Med 2012;47:e1.

17 Withnall C, Shewchenko N, Gittens R, et al. Biomechanical investigation of head impacts in football. Br J Sports Med 2005:39(Suppl 1):i49-57.

18 Fuller CW, Junge A, Dvorak J. A six year prospective study of the incidence and causes of head and neck injuries in international football. Br I Sports Med 2005;39(Suppl 1):i3-9.

19 Andersen TE, Arnason A, Engebretsen L, et al. Mechanisms of head injuries in elite football. Br J Sports Med 2004;38:690-6.

20 Rowson S, Duma SM, Beckwith JG, et al. Rotational head kinematics in football impacts: an injury risk function for concussion. Ann Biomed Eng 2012;40:1-13.

21 Ommaya AK. Biomechanics of Head Injury: Experimental Aspects. In: Nahum AM, Melvin J, eds. The Biomechanics of Trauma. Norwalk, Connecticut: Appleton-CenturyCrofts, 1985: 245-69.

22 King Al, Yang KH, Zhang L. Is head injury caused by linear or angular acceleration? In: Proceedings of the International Research Conference on the Biomechanics of Impacts (IRCOBI), 2003.

23 Bauer JA, Thomas TS, Cauraugh $\mathrm{JH}$, et al. Impact forces and neck muscle activity in heading by collegiate female soccer players. I Sports Sci 2001;19:171-9.

24 Meeuwisse WH, Schneider KJ, Dvořák J, et al. The Berlin 2016 process: a summary of methodology for the 5th International Consensus Conference on Concussion in Sport. Br J Sports Med 2017;51:873-6.

25 Giza CC, Stewart W, Prins ML. Building good policy from good science-The case for concussion and chronic traumatic encephalopathy. JAMA Pediatr 2018:172:803-4.

26 Gardner AJ, Iverson GL, Stanwell P, et al. A video analysis of use of the new "concussion interchange rule" in the National Rugby League. Int I Sports Med 2016;37:267-73

27 Gardner AJ, Kohler R, McDonald W, et al. The use of sideline video review to facilitate management decisions following head trauma in super Rugby. Sports Med Open 2018;4.

28 Burger N, Lambert MI, Viljoen W, et al. Tackle technique and tackle-related injuries in high-level South African Rugby Union under-18 players: real-match video analysis. $\mathrm{Br} \mathrm{J}$ Sports Med 2016;50:932-8.

29 Oehlert K, Drescher W, Petersen W, et al. [Injuries in Olympic handball tournaments: a video analysis]. Sportverletz Sportschaden 2004:18:80-4.

30 Athiviraham A, Bartsch A, Mageswaran P, et al. Analysis of baseball-to-helmet impacts in major leaque baseball. Am J Sports Med 2012:40:2808-14. 